\title{
Preparation and Properties of Paint Prepared with Nanofibrillated Cellulose and Waterborne Epoxy Resin
}

\begin{abstract}
Xin Wang, ${ }^{\text {a,b } *, \# ~ X i ~ W a n g, ~}{ }^{\text {a,b,\# }}$ Yanfei Pan, ${ }^{\text {a,b }}$ Bingbing Zhao, ${ }^{\text {a,b }}$ and Zhanpeng Liang ${ }^{\text {a,b }}$
A new type of water-based paint was prepared with Salix nanofibrillated cellulose (NFC), epoxy resin (E-51), and emulsified curing agent as raw materials. The mechanical blending of coated films was characterized. The mechanical properties and friction and wear properties of the coated film were tested. Microstructure was studied by scanning electron and transmission electron microscopies, thermogravimetric analysis, and other methods. The results showed that when the amount of NFC was $1.0 \%$, the overall performance of the coated film was improved. Herein, the flexibility was $1 \mathrm{~mm}$, the adhesion was 0 , the hardness was $4 \mathrm{H}$, the wear value was $15 \mathrm{mg} / 100 \mathrm{r}$, the impact resistance was $49 \mathrm{~cm}$, and the gloss was $85 \mathrm{Gs}$. The friction and wear coefficient of the composite coated film after the addition of cellulose nanofibers was reduced to 0.171 , which was $58.5 \%$ lower than that before the addition of cellulose nanofibers. The surface observation after abrasion indicated that the composite coated film mainly experienced abrasive wear.
\end{abstract}

DOI: 10.15376/biores.17.1.802-825

Keywords: Nanocellulose; Epoxy resin; Composite coated film; Friction and wear

Contact information: a: College of Materials Science and Art Design, Inner Mongolia Agricultural University, 306 Zhaowuda Road, Hohhot 010018 China; b: Inner Mongolia Key Laboratory of Fibrotic and Energy Development and Utilization of Sandy Shrub Resource, Hohhot 010018 China; ${ }^{\# T h e s e ~ a u t h o r s ~}$ contributed equally to this work; *Corresponding author: wangxin2931@163.com

\section{INTRODUCTION}

Due to the high cross-linking density of epoxy resin (EP) after curing, it is brittle, easily fractured, and has poor friction and wear performance (Shi et al. 2003; Arjmand and Shojaei 2011; Tian et al. 2020). Therefore, it is necessary to add reinforced materials to improve its performance. Natural fibers have the advantages being degradable and having a low cost and therefore are helpful for obtaining high-performance materials (Mohan and Kanny 2011; Sujan et al. 2014; Negi et al. 2019). Among these materials, nanocellulose (NC) is characterized by a large aspect ratio and a large specific surface area (Rahimi et al. 2011). It was combined with water-based EP to prepare a new type of water-based paint. It can improve the comprehensive performance of water-based coatings. The purpose of this work was to evaluate the effects of adding reinforcing materials on the friction and wear properties of EP, thus expanding its application range.

Epoxy resin refers to a thermosetting polymer that contains two or more epoxy groups in its molecular structure and can be cured in a solvent to form a three-dimensional network polymer (Azeez et al. 2013; Jin et al. 2015). The common epoxy resins are oily, and the solvent is an easily volatile alcohol, acetone, etc. Aqueous EP generally refers to the presence of hydrophilic segments in the EP structure, which renders it water soluble. Water is non-toxic, non-flammable, and renewable (Shikha et al. 2003), so it is widely used 
in the field of coatings. The water-borne methods for EP include the following: the mechanical method, chemical modification method, reverse transformation method, and curing agent emulsification method (Chengyin et al. 2007). Sun et al. (2013) used E-51 as a raw material and poly (ethylene glycol) (PEG) in the synthesis of a waterborne epoxy curing agent. Lu et al. (2007) used triethylenetetraamine and E-51 to synthesize a waterborne epoxy hardener. Zhang et al. (2016) synthesized a diglycidyl carboxylate water-based epoxy curing agent using e-44 and triethylene tetramine. Kostrzewa et al. (2011) synthesized a bisphenol A diglycidyl ether modifier using diphenylmethane diisocyanate and polyethylene glycol as raw materials. Liu et al. (2013) synthesized an epoxy resin emulsion with acrylic acid as emulsifier; the formulation was found to have good stability. According to different introduction groups, epoxy curing agents can be divided into ionic curing agents and non-ionic curing agents (Koshevar et al. 2009). Zhang et al. (2017) prepared an epoxy curing agent with E-51 and PEG400 as the raw materials, and its reaction with triethylene tetramine had good water dispersion performance.

Introducing flexible hydrophilic segments into the EP structure not only can improve the shortcomings of EP, such as high brittleness and large internal stress, but it also can reduce the release of VOCs. It has the characteristics of good safety and convenient construction. The epoxy resin structure introduces flexible hydrophilic segments, which makes its friction and wear performance poor ( $\mathrm{Li}$ et al. 2001; Sanes et al. 2010). Accordingly, improving the wear resistance of waterborne epoxy resins has become a problem that needs to be solved. The wear types of waterborne coatings mainly include fatigue wear, abrasive wear, adhesive wear, and chemical wear (Findik 2014). Wear rate and friction coefficient are important parameters that determine the friction and wear performance of composite water-based coatings (Burris et al. 2010). The composite waterbased coating has excellent mechanical strength and chemical properties after modification (Chandran and Radhika 2019). Chang and Zhang (2006) added $\mathrm{TiO}_{2}$ nanoparticles into the $\mathrm{EP}$, and the friction coefficient and wear rate of the composites were considerably reduced. Kang et al. (2012) reduced the friction coefficient of a composite coating after adding modified $\mathrm{SiO}_{2}$ nanoparticles to an EP. Düzcükoğlu et al. (2015) added multi-walled carbon nanotubes and boron nitriding into EP and found that the friction temperature and friction coefficient of the EP decreased. Zhao and Tao (2019) added polytetrafluoroethylene (PTFE) and modified graphene into an EP and the friction coefficient and wear rate of the EP considerably decreased. Raghavendra et al. (2013) prepared EP composites using either natural jute fiber and or glass fiber, and the results showed that the composites with jute fiber had better friction and wear performance.

In the process of modifying water-based coatings, the addition of modifiers will increase the volatilization of organic matter in the coatings. Therefore, this experiment considered the use of plant cellulose as the main material to enhance the water-based epoxy resin, and the effect of the addition of nanocellulose on the material properties was studied. Cellulose widely exists in nature, and its structure contains multiple $\beta-1,4$ glucoside bonds, which are insoluble in organic solvents, e.g., ethanol and acetone (Roy et al. 2009; Dieter et al. 2010; Ribeiro et al. 2019). Nanocellulose, which was subdivided into mainly nanofibrillated cellulose (NFC) and cellulose nanocrystals (CNC). These are isolated from natural fibers and have diameters in the range $1 \mathrm{~nm}$ to $100 \mathrm{~nm}$ (Isogai et al. 2011; Espinosa et al. 2013). In the case of CNC, after the cellulose is hydrolyzed by strong acid, the amorphous area in its structure is destroyed to a greater extent, so that the crystalline domains of the original fine fiber are retained in a large proportion (Bondeson et al. 2006). Compared with CNC, NFC is characterized by a wider size range and a larger aspect ratio, 
presenting a filamentous nanofiber material with a radial nanometer level and an axial micrometer level, and its specific surface area is at least 10 larger than that of cellulose fibers. The length and width of NFC are in micron and nanometer scale, respectively. When they are dispersed in water and other media, it is easy to form networks and structures (Salas et al. 2014), which can improve the properties of composites. Saba et al. (2017) showed that the mechanical properties of composites were considerably enhanced when NFC was added to an EP. Tan et al. (2016) added modified nanocellulose to acrylic coatings, and the Young's modulus, hardness, and wear resistance of the composite coatings were all improved. Cao et al. (2007) added flax nanocellulose to waterborne polyurethane coatings, and the results showed that the Young's modulus and tensile strength were greatly improved.

The cellulose nanofibers composite coated film prepared in this study is mainly used to protect wooden furniture. Considering the external factors in the use process, the hardness, abrasion resistance, and other properties of the prepared composite coated film were studied. Salix NFC and epoxy resin were selected as raw materials. Salix is a natural renewable resource. In this study, Salix NFC was selected as the reinforcing phase of waterbased coatings, since it has low cost and low pollution. In this experiment, six coated film films with different content of NFC were prepared for performance testing. Through comparative analysis, the effect of different contents of NFC on the performance of the coated film was studied, and the optimal amount of NFC added was determined. Through the determination of the friction and wear coefficient, the improvement of NFC on the friction and wear performance of the coated film was studied. The work provides a foundation for the research and application of water-based EP coatings in the protection of wooden furniture.

\section{EXPERIMENTAL}

\section{Materials and Instrument}

Salix nanofibrillated cellulose (NFC, content 1.4\%, diameter of 1 to $100 \mathrm{~nm}$, length $>20 \mu \mathrm{m}$, length to diameter ratio $>200$, and crystallinity $61.9 \%$ ), was purchased from the laboratory of Nanjing Forestry University (Nanjing, China). Epoxy resin (E-51) was purchased from Kunshan Jiurimei Electronic Materials Co., Ltd. commercial grade (Shanghai, China). The emulsifying curing agent was a self-made, propylene glycol methyl ether (PM), while the leveling agent and defoaming agent were purchased from Tianjin Fengcheng Chemical Reagent Technology Co., Ltd (Fengcheng, China). Polyethylene glycol diglycidyl ether (DGEPG), triethylene tetraamine (TETA), and phenyl diglycidyl ether (PGE) were all purchased from the Shanghai Maclean Biochemical Technology Co., Ltd (Shanghai, China). Acetone, analytically pure, was purchased from Li'an Longbohua Pharmaceutical Chemical Co., Ltd. (Shanghai, China).

\section{Methods}

Preparation of the emulsifying curing agent

A suitable amount of TETA was added into three flasks, and the condenser tube and stirrer were connected. The speed was adjusted to $250 \mathrm{r} / \mathrm{min}$. A water bath was heated to a temperature of $65^{\circ} \mathrm{C}$, and an appropriate amount of DGEPG was dropped into a threemouth flask at a uniform rate. The addition product was obtained after a $3 \mathrm{~h}$ reaction, which was followed by further heating. When the temperature reached $75^{\circ} \mathrm{C}$, an appropriate 
amount of E-51 dissolved by PM was added and reacted for $3 \mathrm{~h}$ to obtain the synthetic product. Appropriate amount of E-51 dissolved by $\mathrm{PM}$ was added at $75^{\circ} \mathrm{C}$ and reacted for $3 \mathrm{~h}$. The emulsifying curing agent was formed when the temperature reached $70{ }^{\circ} \mathrm{C}$, and an appropriate amount of end sealing agent (PGE) was added while spinning at $300 \mathrm{r} / \mathrm{min}$.

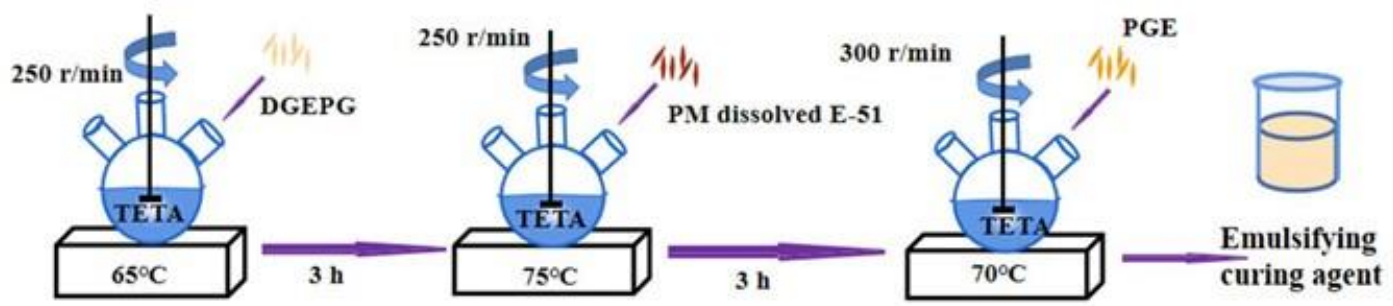

Fig. 1. Flowchart of preparation of the emulsifying curing agent

\section{Salix Preparation of NFC acetone solution}

An appropriate amount of Salix nanocellulose was added into a $250 \mathrm{~mL}$ beaker, and $200 \mathrm{~mL}$ of distilled water was added. While remaining in an ice bath, ultrasonic treatment was performed on the cellulose with an ultrasonic processor until the nanocellulose was evenly dispersed in the aqueous solution. After allowing the aqueous solution to stand, the distilled water was replaced and removed with acetone to obtain the NFC acetone solution.

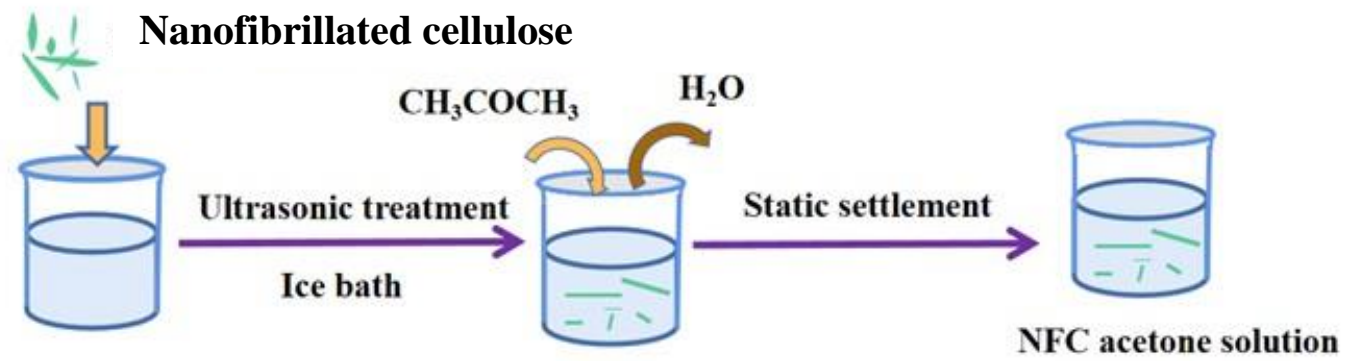

Fig. 2. Flowchart of preparation of Salix preparation of NFC acetone solution

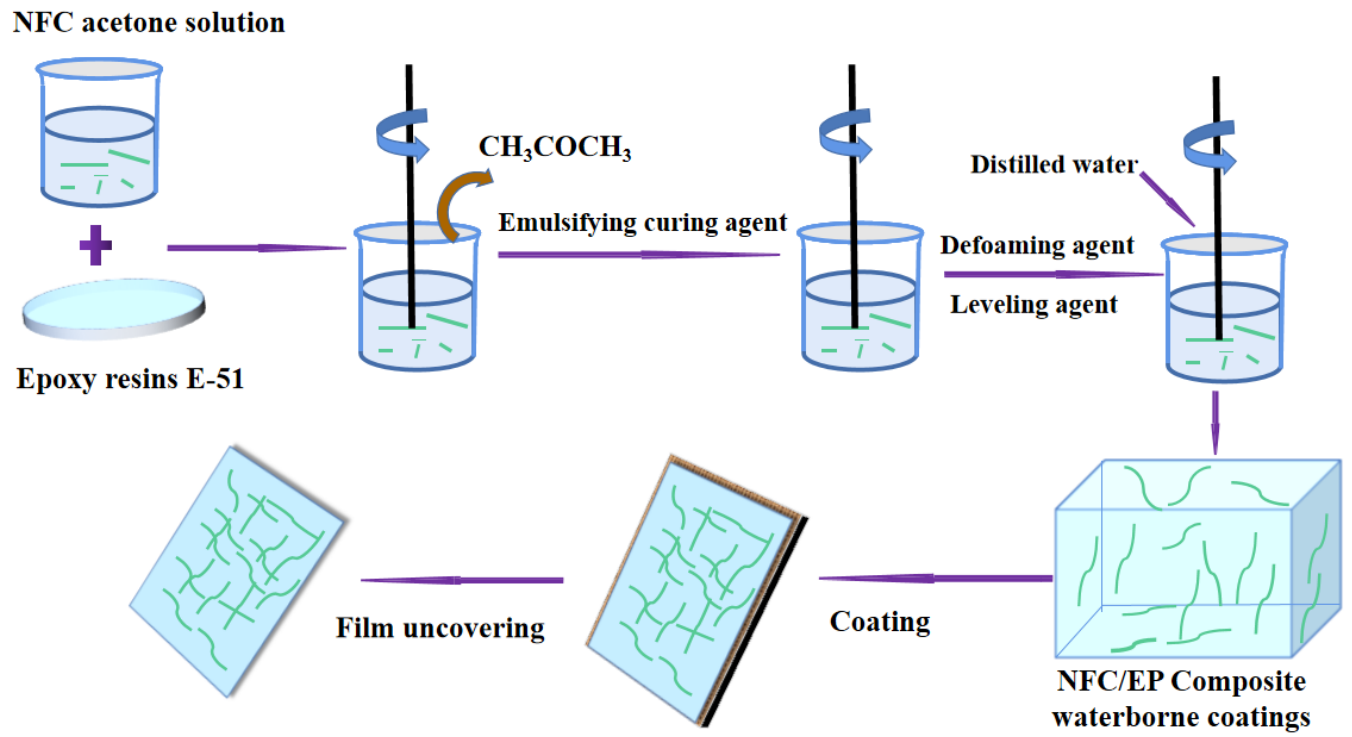

Fig. 3. Flowchart of preparation of the water-based coated film of NFC composite epoxy resin 
Preparation of NFC composite epoxy resin water-based paint

The NFC acetone solution prepared above was added to the epoxy resin (E-51) and evenly stirred until the acetone was volatilized. Then, the emulsifying curing agent, distilled water, defoaming agent, and leveling agent were added and emulsified via highspeed dispersion homogenizer. Afterwards, the NFC composite EP water-based coating was evenly stirred. The coating was applied to the tinplate or wood material, and the coating thickness was controlled at 20 to $40 \mu \mathrm{m}$. The waterborne coated film that was evaluated in the experiment was obtained after natural air drying.

Testing and characterization film performance test

The surface drying and hard drying time were tested according to GB/T standard 1728 (1989). The water resistance was tested according to GB/T standard 9274(1988). The adhesion was tested according to GB/T standard 5210 (2006). The flexibility was tested according to GB/T standard 1731 (1993). The hardness was tested according to GB/T standard 6773 (1996). The wear resistance was tested according to GB/T standard 4893.8 (2013). The impact resistance was tested according to GB/T standard 4893.8 (2013). The gloss was tested according to GB/T standard 9754 (2007). The gloss was tested by the measurement of $20^{\circ}, 60^{\circ}$ and $85^{\circ}$ specular gloss of color paints and varnishes without to GB/T standard 9754 (2007).

\section{Characterization of Salix cellulose nanofibers}

The morphology of Salix NFC was evaluated using SEM. The specific surface area and pore size analyzer (BSD-PSI) was used to test the specific surface area of NFC after ultrasonication. The Malvern 3000 laser particle size analyzer was used for DLS tests. The test range was 0 to $2000 \mu \mathrm{m}$. Each sample was tested three times, and the average value was taken.

\section{Reciprocating friction and wear test}

Before the test, the samples were polished with 800\# sandpaper and cleaned with aqueous ethanol. The test conditions were as follows: the friction frequency was $1 \mathrm{~Hz}$, the load was $0.5 \mathrm{~N}$, the travel distance was $10 \mathrm{~mm}$, and a normal temperature environment was worked for $30 \mathrm{~min}$. A curve diagram of the friction time and friction coefficient was obtained.

\section{Scanning electron microscopy (SEM) test}

A small amount of each of the samples were placed on the instrument base, and after being vacuumizing and gold sputtered, the surface and section morphology of the sample were tested to obtain the sample morphology.

\section{Thermal stability test}

The samples were placed in a $\mathrm{N}_{2}$ environment with a gas flow rate of $20 \mathrm{~mL} / \mathrm{min}$, a heating rate of $10{ }^{\circ} \mathrm{C} / \mathrm{min}$, and a temperature range of 20 to $800{ }^{\circ} \mathrm{C}$. The thermogravimetric curves of the samples were obtained to analyze their thermal stability.

\section{Contact angle analysis}

The contact angles of the samples were measured via fixation titration using a $\mathrm{jY}$ PHA interfacial tension meter. The droplet stabilization time of each sample was controlled to be 3 to $4 \mathrm{~s}$. 
$X$-ray diffraction (XRD) analysis

An X-ray diffractometer was used to scan the coated film samples. The test conditions were as follows: a tube pressure of $40 \mathrm{KV}$, a tube flow of $200 \mu \mathrm{A}$, a $\mathrm{Cu}$ target, a diffraction width of DS (Divergence slit) $=\mathrm{SS}$ (Anti-scatter slit) $=1^{\circ}$, a RS (Receiving slit $)=0.3 \mathrm{~mm}$, a scanning speed of $2.000\left(\mathrm{~d} \cdot \mathrm{min}^{-1}\right)$, and a scanning ranging of $5^{\circ}$ to $90^{\circ}$. The XRD patterns were obtained and compared.

Dynamic Mechanical Thermal Analysis (DMA) test

Through the DMA-Q800 dynamic mechanical analyzer, the tensile mode was used for testing. The initial condition of all samples in the DMA is $0{ }^{\circ} \mathrm{C}$, and the test temperature was 0 to $150{ }^{\circ} \mathrm{C}$. The dynamic heating scan was carried out in the range of $2{ }^{\circ} \mathrm{C} / \mathrm{min}$ and $10 \mathrm{~Hz}$.

Transmission electron microscopy (TEM) test

After diluting the sample with ethanol to a concentration of approximately $1 \%$, the sample was evenly dispersed in the solution via ultrasonic treatment, and then it was dropped on the copper net and dried. The apparent structure of the samples was tested via transmission electron microscopy at an accelerating voltage of $200 \mathrm{kV}$.

\section{Scratch friction and wear test}

Using MTF-5000 multifunctional friction and wear tester from Atech Instrument Technology Co., Ltd., the scribe head was a steel ball, the material was GCr15, the diameter was $2 \mathrm{~mm}$, and the load was 0.2 to $10 \mathrm{~N}$. The load rate was $5 \mathrm{~N} / \mathrm{min}$, with a stroke of 20 $\mathrm{mm}$, at room temperature. The scribe head works at a speed of $0.1667 \mathrm{~mm} / \mathrm{s}$ for $120 \mathrm{~s}$. With these settings, the topography of the scratch was obtained.

\section{RESULTS AND DISCUSSION}

\section{The Characterization of NFC from Salix}

Dynamic Light Scattering (DLS) is a widely used method to obtain the statistical size distribution of cellulose nanoparticles in suspension. However, it is important to highlight that DLS measurements consider that all the particles are spherical, and the size values depend on the orientation of the fibers in suspension (Carvalho Benini et al. 2018). NFC has micro-level and nano-level components. After being diluted, micro-level NFC is easy to settle and agglomerate during the test. The average particle size tested is relatively large. It can be seen from Table 2 that the more NFC content, the larger the average particle size and the lower the uniformity. Since the sample was diluted before the test, the difference in particle size distribution and uniformity was not obvious. A trend could still be obtained, that the more NFC content, the lower the uniformity of its distribution, which indicates that the increase in NFC content leads to agglomeration.

Table 1. Specific Surface Area and Pore Volume of Salix Nanocellulose

\begin{tabular}{|c|c|c|}
\hline The Sample & $\mathrm{BET}\left(\mathrm{m}^{2} / \mathrm{g}\right)$ & Standard deviation \\
\hline Salix NFC & 8.181 & 0.0726 \\
\hline
\end{tabular}




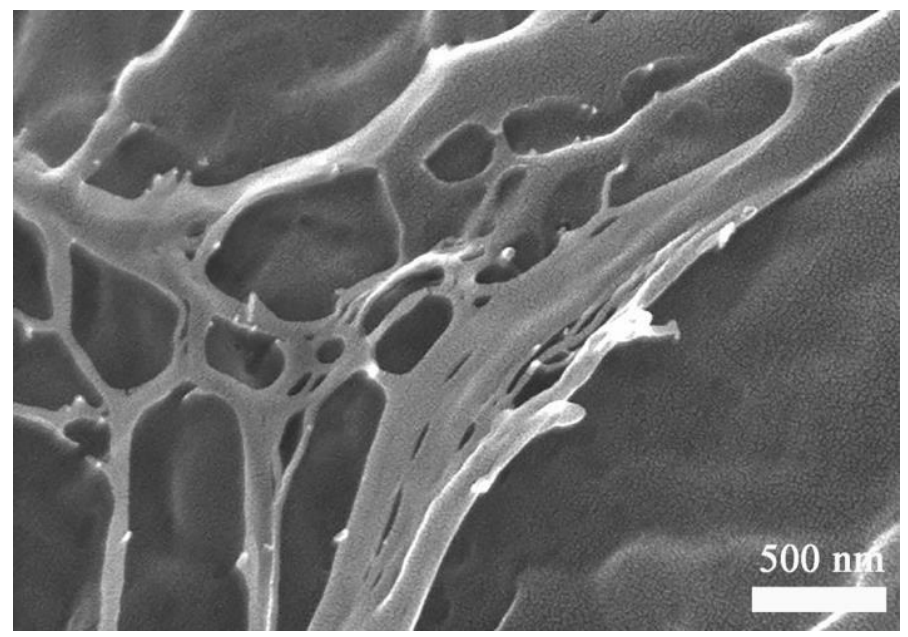

Fig. 4. SEM images Salix NFC after ultrasonic and drying at $500 \mathrm{~nm}$

Table 2. DLS Analysis Results

\begin{tabular}{|c|c|c|c|c|}
\hline Sample Name & $\begin{array}{c}\text { Volume weighted } \\
\text { mean (Average.um) }\end{array}$ & $\begin{array}{c}\text { Surface weighted } \\
\text { mean (Average.um) }\end{array}$ & $\begin{array}{c}\text { Uniformity } \\
\text { (Average) }\end{array}$ & $\begin{array}{c}\text { Uniformity } \\
\text { (Standard } \\
\text { deviation) }\end{array}$ \\
\hline $0.5 \%$ NFC & 107.531 & 28.292 & 1.84 & 0.0432 \\
\hline $1.0 \% N F C$ & 108.505 & 28.547 & 1.78 & 0.0047 \\
\hline $1.5 \% N F C$ & 109.039 & 28.792 & 1.78 & 0.0125 \\
\hline $2.0 \% N F C$ & 109.734 & 28.848 & 1.75 & 0.0094 \\
\hline $2.5 \% N F C$ & 122.366 & 29.978 & 1.73 & 0.0125 \\
\hline
\end{tabular}

After the ultrasonically dispersed NFC was dried, the SEM test was performed to obtain the morphology of the NFC. From Fig. 4, it can be seen that after ultrasonic dispersion, nano-cellulose is decomposed into filaments, and after drying, NFC are crosslinked to form a network structure. Table 1 can obtain the specific surface area of the NFC. Perform six BET tests on the NFC, and the average BET value was $8.181 \mathrm{~m}^{2} / \mathrm{g}$.

\section{Effect of the Cellulose Nanofibrils (NFC) Dosage on the Mechanical Properties of the Composite Coated Film}

As shown in Fig. 5a, the surface drying time and hard drying time gradually increased as the NFC dosage increased, while the water resistance time gradually decreased. According to the properties of coated films, the composite coated films drying stage consists of surface drying and absolute drying. In addition, the drying process may be influenced by internal factors, e.g., the nature of the raw materials, water, solvent volatilization degree, etc. At the same time, the drying process can be influenced by external factors, e.g., temperature and humidity, illumination, etc., so all the coated films in the testing process will be in the same environmental conditions. As can be seen from 
Fig. 5a, after adding the NFC, the surface drying and actual drying time increased for the composite coated films. This is because the NFC surface has a large amount of -OH groups; with the addition of NFC into the coating system, it may interact with the water molecules in the air, which may also affect the evaporation of water molecules in water-based coatings, thus prolonging the coating drying time. At the same time, the presence of NFC also causes incomplete cross-linking reactions between the epoxy group in the waterborne $\mathrm{EP}$ and the amino group in the waterborne curing agent, resulting in a decrease in the water resistance of the composite coated films.

Figure $5 b, 5 c$, and $5 d$ show that after the addition of NFC, the flexibility, adhesion, hardness, wear value, and impact resistance of the composite waterborne coated film were increased, while the gloss range decreased.

Wear resistance refers to the resistance of a coated film to mechanical wear, which occurs when the coated film is subjected to a certain frictional force. In this test, the coated film was placed under a rotating rubber grinding wheel and the coated film mass loss was used to illustrate the wear resistance of the coated film after 100 turns. Figure 5b shows that the wear value before the addition of NFC was $32 \mathrm{mg} / 100 \mathrm{r}$. The wear resistance of the composite coated film increased considerably after adding NFC; the lowest wear value was $15 \mathrm{mg} / 100 \mathrm{r}$, which was an increase of 53.13\%. In addition, after adding the NFC, the hardness and impact resistance of the composite coated film also had a major increase, where the maximum hardness reached $4 \mathrm{H}$, while the maximum impact resistance reached $49 \mathrm{~cm}$. There are a large number of hydroxyl groups on the surface of NFC, which can form hydrogen bonds with epoxy resin, and the van der Waals force between molecules is enhanced. The addition of NFC contributes to the bonding strength between the interface and the fiber in the EP matrix, and the interface force is enhanced, thus showing composite coated film have high hardness. The large number of hydroxyl groups on the surface of NFC make the NFC and EP matrix tightly combined. Under the action of external force, NFC is not easy to break away from the epoxy resin matrix and can transmit external force well. Then local yield deformation occurs in the surrounding matrix, which increases the impact resistance (Yu et al. 2013). At the same time, NFC has the characteristics of large aspect ratio, high mechanical strength, large specific surface area, which can overlap each other in the coated film to form a network structure, which enhances the wear resistance. (Zhang et al. 2016).

Adhesion is the force between the coated film and the substrate coated. As shown in Fig. 5c, after the addition of NFC, the composite coated film rising increased to a level 0 adhesion, and the flexibility simultaneously increased to $1 \mathrm{~mm}$. This is because the NFC has a high elastic modulus under external force. As such, the NFC, which can withstand most forces throughout the entire structure, reduces the damage to the coated film. At the same time, hydrogen bonds are produced between the NFC and the water-based EP segment, which can absorb most of the energy, and reduce the destruction of chemical bonds in the compound. Therefore, with the addition of NFC, the adhesion and flexibility of the composite coated film was improved. As the content of NFC increases, the proportion of hydrogen bonding by itself increases. When impacted, greater plastic deformation and development of macroscopic cracking will occur, and the physical and mechanical properties of the coated film will decrease instead.

Glossiness is a surface characteristic of a substance, which primarily depends on the reflection degree of light on the surface of the substance. It is also related to the surface structure of the substance. Figure 5d shows that pure EP had the highest gloss (106 Gs), and after the addition of NFC, the glossiness value decreased to as low as approximately 
40 Gs. When NFC was added into EP, NFC molecules between forces will lead to agglomeration, and with more content of NFC, the agglomeration phenomenon more obvious. Therefore, when light irradiates the composite coated film, the diffuse reflection of light will occur, and the glossiness will be reduced.
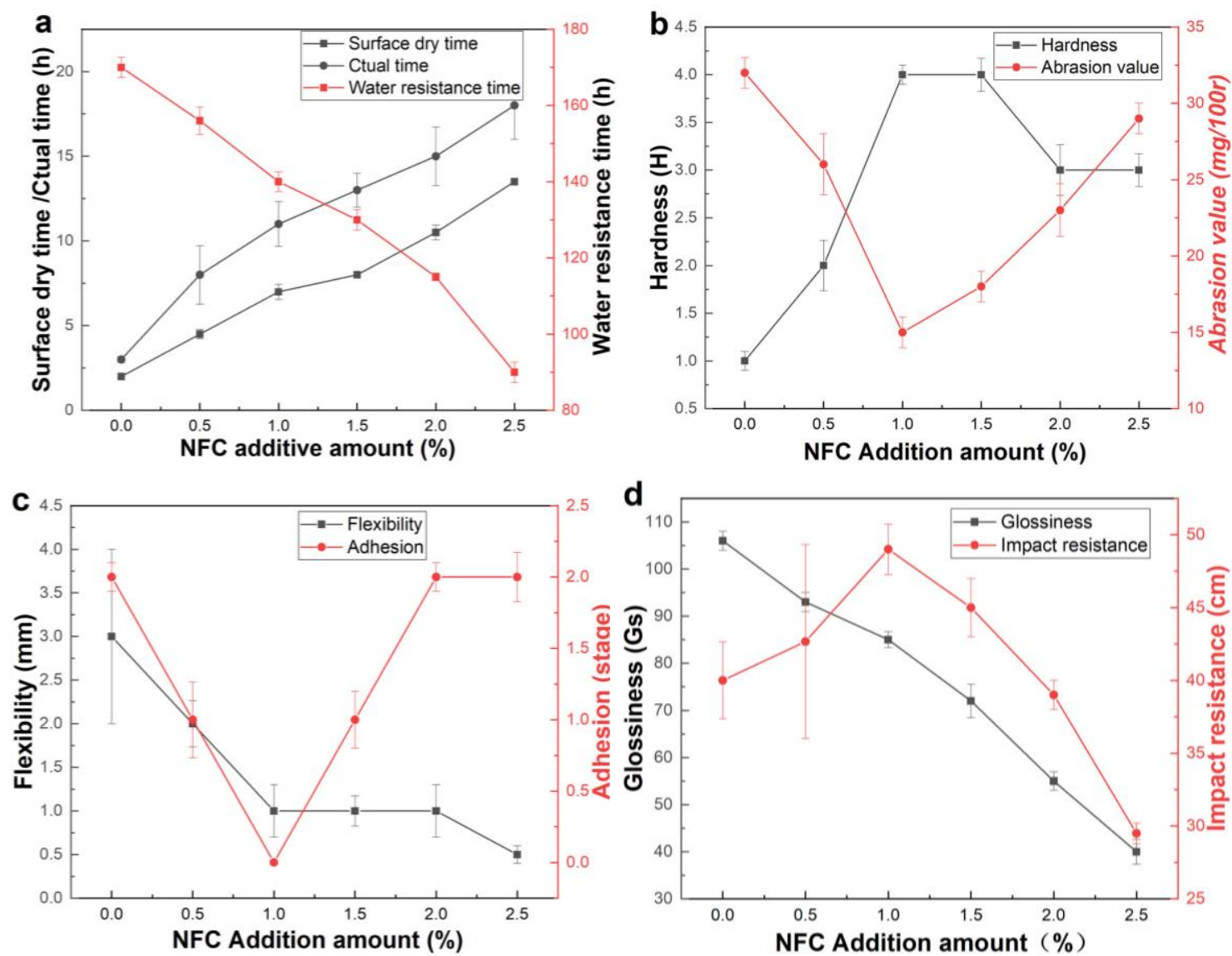

Fig. 5. The effect of the addition of NFC on the mechanical properties of the composite coated film (a: The effect of the addition of NFC on the drying time and the water resistance time of the composite coated film. b: The effect of the addition of NFC on the hardness and the abrasion value of the composite coated film. c: The effect of the addition of NFC on the flexibility and the adhesion of the composite coated film. d: The effect of the addition of NFC on the glossiness and the impact resistance of the composite coated film.)

\section{Scanning Electron Microscopy (SEM) Analysis of the Nanofibrillated Cellulose (NFC) Composite Epoxy Resin (EP) Waterborne Coated Film}

Epoxy thermosetting materials are relatively brittle, so the use of nanoparticles to toughen them has become a common method (Domun et al. 2015). SEM analysis was performed on the cross-section of the sample, and the cross-sectional characteristics of different samples were analyzed by observing the difference in fracture morphology (Thomas et al. 2008). Combined with the plan view of the samples, the influence of different NFC content on the coated film was compared. Two groups of samples were selected with obvious difference in fracture mode to perform tensile stress test, and the tensile stress curve was obtained as shown in Fig. 7. The SEM images show the pure EP and the samples with different NFC contents. Figures $6 \mathrm{a}$ and $6 \mathrm{~b}$ show the plane and cross 
section of the pure EP film sample, respectively. In Fig. 6a, it can be observed that the surface of the pure EP coated film was quite smooth. However, due to the incomplete reaction of the epoxy resin colloidal particles in the coating, the evaporation of water makes the epoxy resin colloidal particles contact and accumulate during the curing and film forming process, resulting in a few defects. Figure $6 \mathrm{~b}$ shows the cross-section of the coated film after impact fracture. The section is smooth, with only a few cracks, and a large stripe texture, which is a typical brittle fracture feature (Wu et al. 2012). According to the pure EP tensile-stress curve shown in Fig. 7, the fracture type of the sample can be obtained as brittle fracture. Figures $6 \mathrm{c}$ and $6 \mathrm{~d}$ show the plane and cross section of the $0.5 \%$ NFC sample. It was observed that the plane of the $0.5 \%$ NFC composite EP coated film was smooth and uniform, and white parts can be seen at the edge of the lines on the section. This phenomenon indicated that when the NFC was added to the EP, the section of cracks increased when compared to the pure EP coated film, and a few scaly cracks appeared. Figures $6 \mathrm{e}$ and $6 \mathrm{f}$ show the plane and cross section images of the $1.0 \%$ NFC sample, and more abundant and obvious white parts can be observed, which indicated that the NFC was evenly distributed throughout the coated film. In addition, it can be seen from Fig. $6 f$ that the amount of rough scaly cracks increased, showing an obvious ductile fracture.

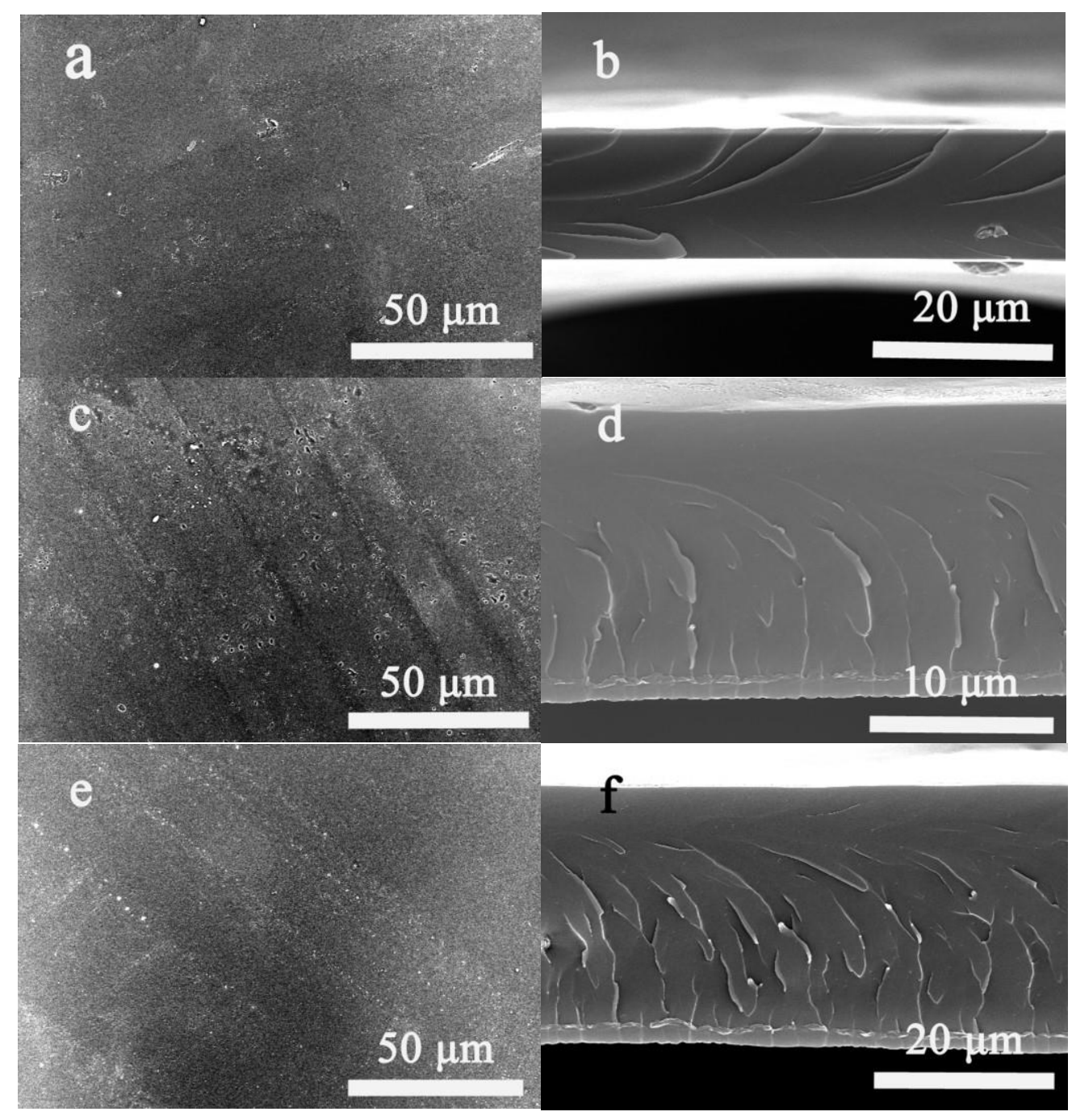




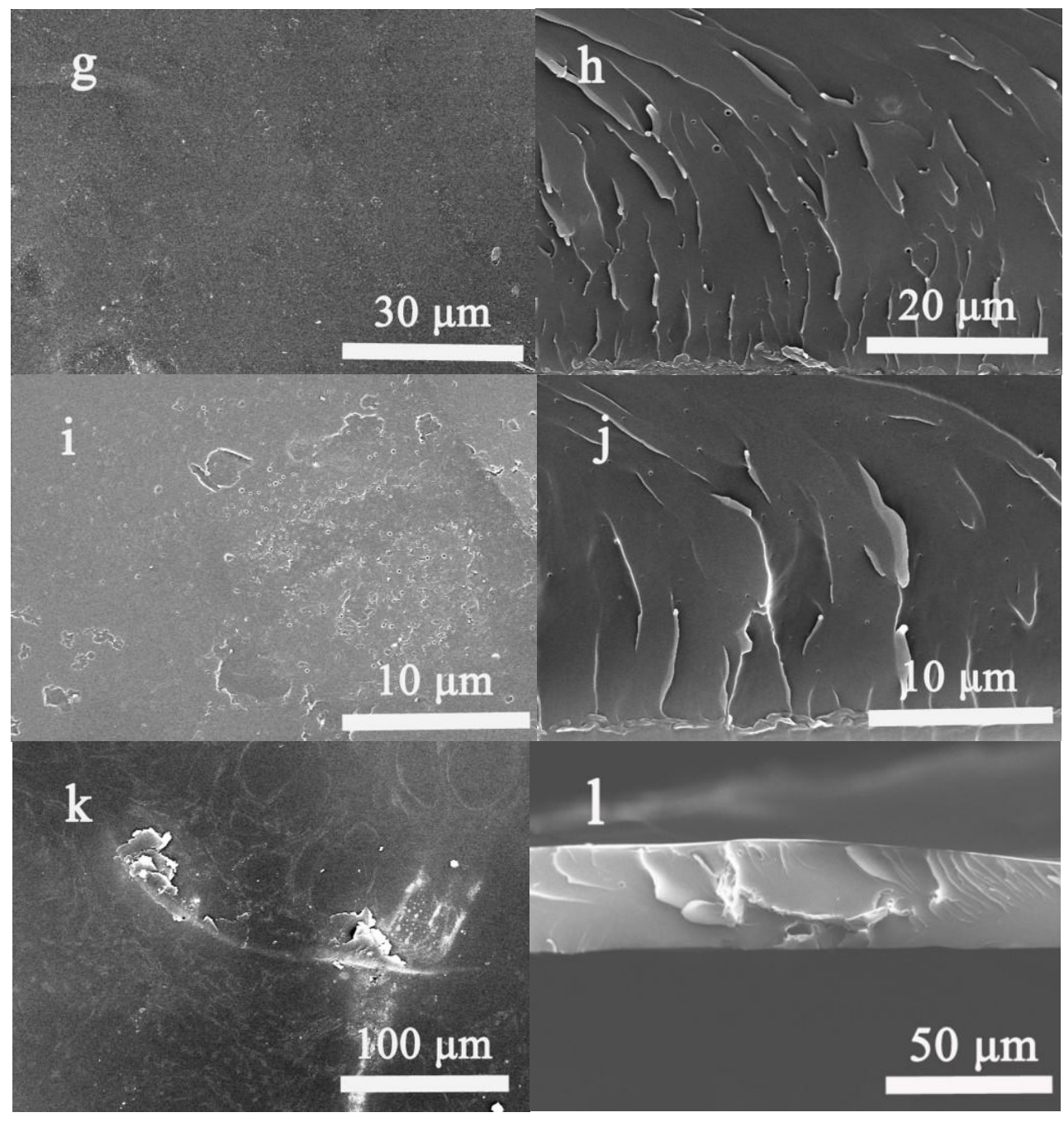

Fig. 6. SEM images of the pure EP sample and the different NFC content composite water-based paint samples ( $a$ and b: SEM of Plane and Section of Pure EP, $c$ and d: SEM of Plane and Section of $0.5 \%$ NFC, e and $\mathrm{f}$ : SEM of Plane and Section of $1.0 \% \mathrm{NFC}, \mathrm{g}$ and $\mathrm{h}$ : SEM of Plane and Section of $1.5 \%$ NFC sample, i and j: SEM of Plane and Section of $2.0 \% N F C$, $k$ and I: SEM of Plane and Section of $2.5 \%$ NFC)

The tensile stress curve shown in Fig. 7 also shows that the fracture mode of the coated with the addition of $1.0 \%$ NFC was a ductile fracture, indicating that the NFC content resulted in a certain improvement on the mechanical properties of the composite waterborne coated film. Figures $6 \mathrm{~g}$ and $6 \mathrm{~h}$ show the plane and cross section images of the $1.5 \%$ NFC sample. There were a large number of scaly cracks and a uniform distribution, while the fold of the section was rough and compact. Figures $6 \mathrm{i}$ and $6 \mathrm{j}$ show the plane and cross section images of the $2.0 \%$ NFC sample. It can be seen that the surface of the coated film was not uniform and had spiral lines. As shown in Fig. 6j, the size and distribution of the scaly cracks were not uniform. Figures 6k and 61 show the SEM images of the plane and cross section of the $2.5 \%$ NFC sample. Figure 6k shows obvious white spiral parts, which indicated the agglomeration of a large number of NFC particles. Figure 61 was observed that the distribution of the NFC was very uneven, with considerable agglomeration. 

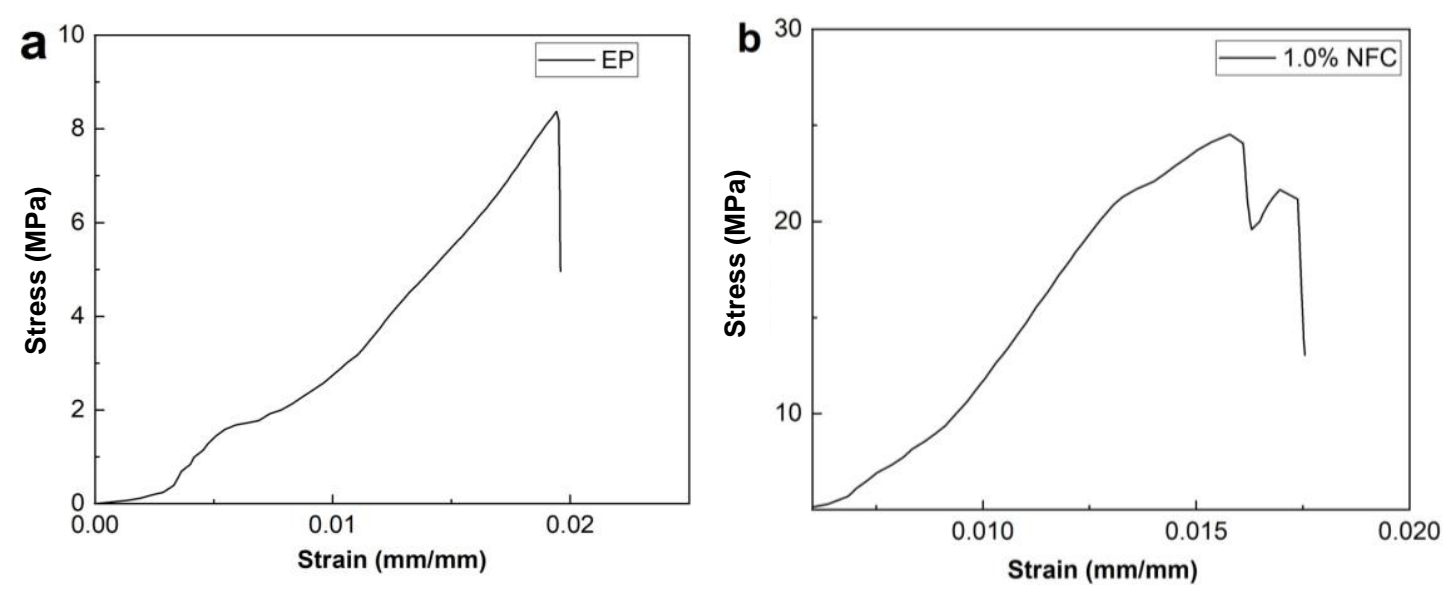

Fig. 7. Tensile stress curve image of the pure EP and the 1.0\% NFC composite water-based coated film (a: Tensile stress curve image of the pure EP, b: S Tensile stress curve image of the $1.0 \%$ NFC composite water-based coated film)

According to the SEM image, it can be concluded that adding an appropriate amount of NFC can improve the flexibility of EP water-based coated film. Since NFC has good mechanical properties, the mechanical properties of the composite coated film were improved. The high length-width ratio and larger specific surface area of the NFC can enhance the interfacial adhesion between the NFC and EP matrix. This effectively combines the NFC with the EP system, so as to realize the stress transfer from the matrix to the reinforcing phase. When the coated film breaks, the stress can be buffered, and the force can be dispersed through the crack produced by the fracture, so the flexibility of the coated film is improved. The NFC content determines the extent of the crack, which also determines the area of the fracture surface. The larger the area, the more energy that can be dissipated, thus improving the fracture toughness. However, due to the increase in NFC content, the NFC easily agglomerates in the EP waterborne coated film, making the NFC distribution uneven. This results in the concentration of stress, and the mechanical properties of the coated film portions without NFC are reduced, forming weak parts. When the coated film is acted on by external forces, the weak parts can be destroyed very easily, which makes the overall mechanical strength and flexibility of the coated film decrease. Therefore, the key to improving the mechanical properties of the coated film is to control the amount of NFC added. In conclusion, the mechanical properties of the samples coated with $1.0 \%$ NFC and $1.5 \%$ NFC were the highest, so these two amounts of NFC should be the first choices for composite EP waterborne coatings.

\section{Thermal Stability Analysis of the Cellulose Nanofibrils (NFC) Composite Epoxy Resin (EP) Waterborne Coated Film}

Thermogravimetric analysis was performed on the coated film samples with different contents of NFC, analyze the effect of adding NFC on the thermal stability of coated film. Adding polymer in the preparation of composite materials can change the thermal stability of the material (Giorcelli et al. 2019). For most natural fibers approximately $60 \%$ of the thermal decomposition occurred within a temperature range between 215 and $310^{\circ} \mathrm{C}$ (Fei et al. 2008). The maximum thermal decomposition peak of Salix cellulose reaches $353{ }^{\circ} \mathrm{C}$ (Zhong et al. 2021). Figure 8a shows the TG curves of the pure EP coated film and the coated film with five different NFC contents. 

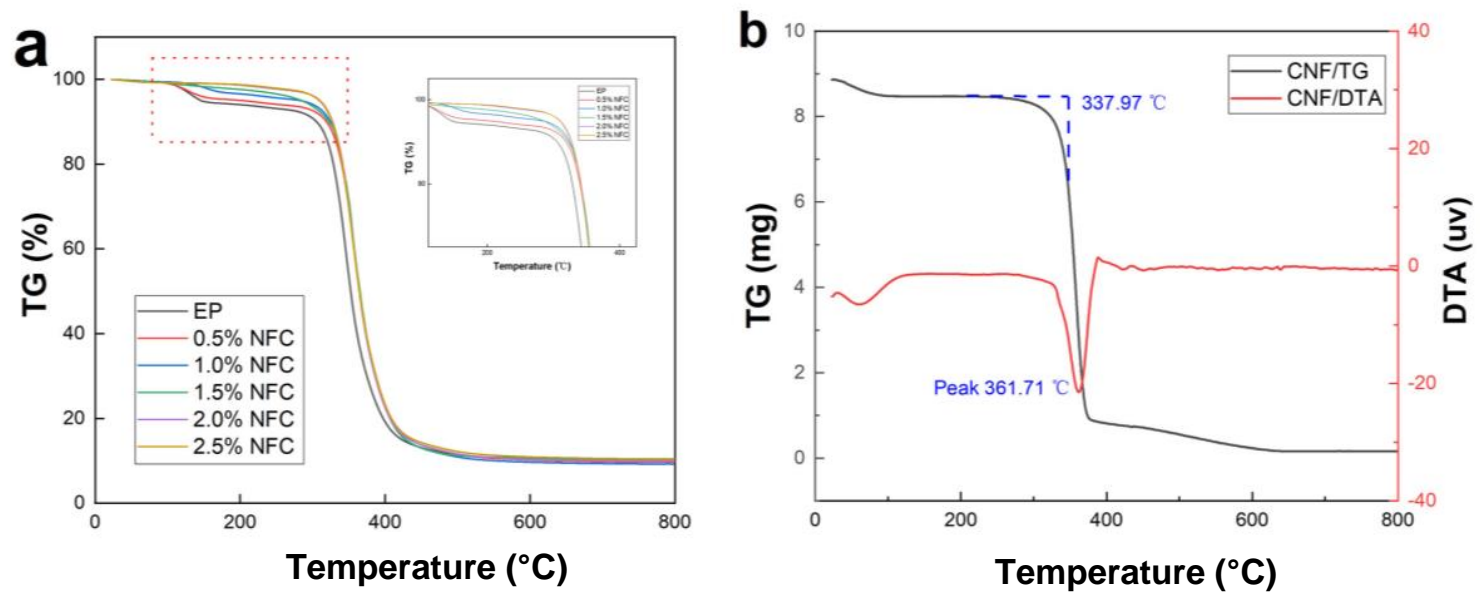

Fig. 8. Thermogravimetric curve (a: The TG curve of the pure EP sample and the different NFC content composite water-based paint samples. b: The TG and DTA curves of NFC.)

Table. 3 Thermogravimetric Analysis Results

\begin{tabular}{|c|c|c|c|c|c|}
\hline $\begin{array}{c}\text { The } \\
\text { Sample }\end{array}$ & $T_{5 \%}\left({ }^{\circ} \mathrm{C}\right)$ & $T_{10 \%}\left({ }^{\circ} \mathrm{C}\right)$ & $T_{\operatorname{MAX}}\left({ }^{\circ} \mathrm{C}\right)$ & $T_{50 \%}\left({ }^{\circ} \mathrm{C}\right)$ & IPDT $\left({ }^{\circ} \mathrm{C}\right)$ \\
\hline EP & 145.8 & 305.5 & 358.2 & 352.5 & 427.58 \\
\hline $0.5 \%$ NFC & 202.9 & 319.1 & 371.5 & 364.3 & 438.88 \\
\hline $1.0 \%$ NFC & 283.1 & 324.3 & 371.7 & 364.7 & 441.52 \\
\hline $1.5 \%$ NFC & 284.6 & 322.5 & 372.3 & 365.3 & 445.88 \\
\hline $2.0 \%$ NFC & 310.1 & 326.9 & 373.1 & 364.4 & 448.51 \\
\hline $2.5 \%$ NFC & 309.3 & 332.1 & 380.9 & 364.5 & 451.13 \\
\hline
\end{tabular}

Figure $8 \mathrm{~b}$ shows the TG and DTA curves of NFC. It can be seen from Fig. $8 \mathrm{~b}$ that Salix NFC ended the initial pyrolysis process at $338.0^{\circ} \mathrm{C}$ and entered the rapid pyrolysis process, with the maximum weight loss peak at $361.7^{\circ} \mathrm{C}$. Therefore, NFC had higher thermal stability than EP. As can be seen from Fig. 8a, the initial pyrolysis reaction of the sample occurred at temperatures between 104.5 and $146.9^{\circ} \mathrm{C}$, while the weight loss rate within unit temperature of the pure EP sample was the highest (5\%). This was because the EP system was unstable at this temperature, and the water and organic solvents in the waterborne coated film evaporated. The other samples also showed weight loss at temperatures between 104.5 and $146.9^{\circ} \mathrm{C}$. The curves of the $2.0 \%$ NFC and $2.5 \%$ NFC samples were the gentlest, and the weight loss rate was only $0.93 \%$, which indicated that the 2.0\% NFC and 2.5\% NFC samples showed good stability at this temperature. The pure EP sample entered the rapid weight loss stage after reaching a temperature of $303.8^{\circ} \mathrm{C}$, and the TG curve was gentle at a temperature of $424.2{ }^{\circ} \mathrm{C}$. The rapid weight loss stage of the samples containing NFC ranged occurred at a temperature range of 335.1 to $446.3{ }^{\circ} \mathrm{C}$. As can be seen from Table 3, when the weight loss rate was $5 \%$, the corresponding temperature of the pure EP sample was $145.8^{\circ} \mathrm{C}$, and the corresponding temperature of the $0.5 \%$ NFC sample and the other coated films containing NFC ranged from 202.9 to $309.3{ }^{\circ} \mathrm{C}$. As the NFC content increased, the corresponding temperature also increased. According to the corresponding temperature changes of the other pyrolysis reaction processes shown in Table 3, the pyrolysis temperature of the EP water-based coated film with the addition of NFC was higher the pyrolysis temperature of the pure EP sample, and its thermal stability is improved. 
The integral program decomposition temperature method (IPDT) was used for analysis (Doyle 1961). The area under the thermogravimetric curve was used to analyze the thermal stability of the polymer. The area $(A)$ under the TG curve was expressed as a fraction of the total area of the figure and calculated as $A^{*}=X$, and then $A^{*}$ was converted to the temperature $T_{\mathrm{A}} *$ by the equation $\left(T_{\mathrm{A}} *=875 A^{*}+25\right)$, where TA is a hypothetical temperature, whereby if one puts $A=X$ into the calculation, the results is $T_{\mathrm{A}}=Y$. It can be seen from the Table 3 that as the temperature continues to increase, the IPDT value gradually increases.

Based on the analysis of the above TG curves and IPDT, it can be concluded that the addition of NFC can improve the thermal stability of EP waterborne coated film. The thermal stability of a material depends on the chemical bond inside the molecule, and NFC primarily forms hydrogen bonds and other ways to promote crystallization. Therefore, the addition of NFC to an EP waterborne coated film increases the number of hydrogen bonds, thus enhancing the chemical bonds, and improving the stability is improved. In addition, as the NFC is dispersed throughout the EP waterborne coated film, the hydroxyl groups on the surface form a three-dimensional network structure with the EP matrix via hydrogen bonding, which improves its thermodynamic performance. At the same time, due to the low thermal expansion coefficient of NFC, and its own structure being stable, the addition of NFC can improve thermal stability of composite waterborne coated film to some extent.

\section{Contact Angle Analysis of the Cellulose Nanofibrils (NFC) Composite Epoxy Resin (EP) Waterborne Coated Film}

NFC has a hydrophilic nature, which can be the main drawback for its use (Fahma et al. 2014). Using NFC as composite materials, attention should be paid to the hydrophobicity of the composite materials. Figure 9 shows the contact angle images of the pure EP and NFC/EP water-based coated film. Figure 9a shows the contact angle image of the pure EP, which is a hydrophobic material. After adding $0.5 \%$ content of NFC, the contact angle shows that the composite waterborne coated film was still hydrophobic, but the contact angle became smaller, indicating that the hydrophobicity had changed (as shown in Fig. 9b). Figure 9c shows the contact angle of the coating with $1.0 \%$ content of NFC, and the coated film was still hydrophobic. Figure 9d, 9e, and 9f are the contact angle images of the waterborne coated film with $1.5 \%, 2.0 \%$, and $2.5 \%$ NFC content. As the NFC content increased, the number of hydrophilic groups in the coated film increased; therefore, the coated film gradually changed from hydrophobic to hydrophilic. As such, under the premise of ensuring the hydrophobicity of the coated film, the addition of $1.0 \%$ NFC is the best choice for this composite coated film.

Table 4. Contact Angle Results

\begin{tabular}{|c|c|c|}
\hline NC Content & Contact Angle $\left({ }^{\circ}\right)$ & Standard Deviation \\
\hline $0 \%$ & 105.8 & 0.939 \\
\hline $0.5 \%$ & 95.0 & 0.849 \\
\hline $1.0 \%$ & 90.0 & 0.124 \\
\hline $1.5 \%$ & 84.5 & 0.648 \\
\hline $2.0 \%$ & 80.7 & 0.286 \\
\hline $2.5 \%$ & 78.6 & 0.895 \\
\hline
\end{tabular}



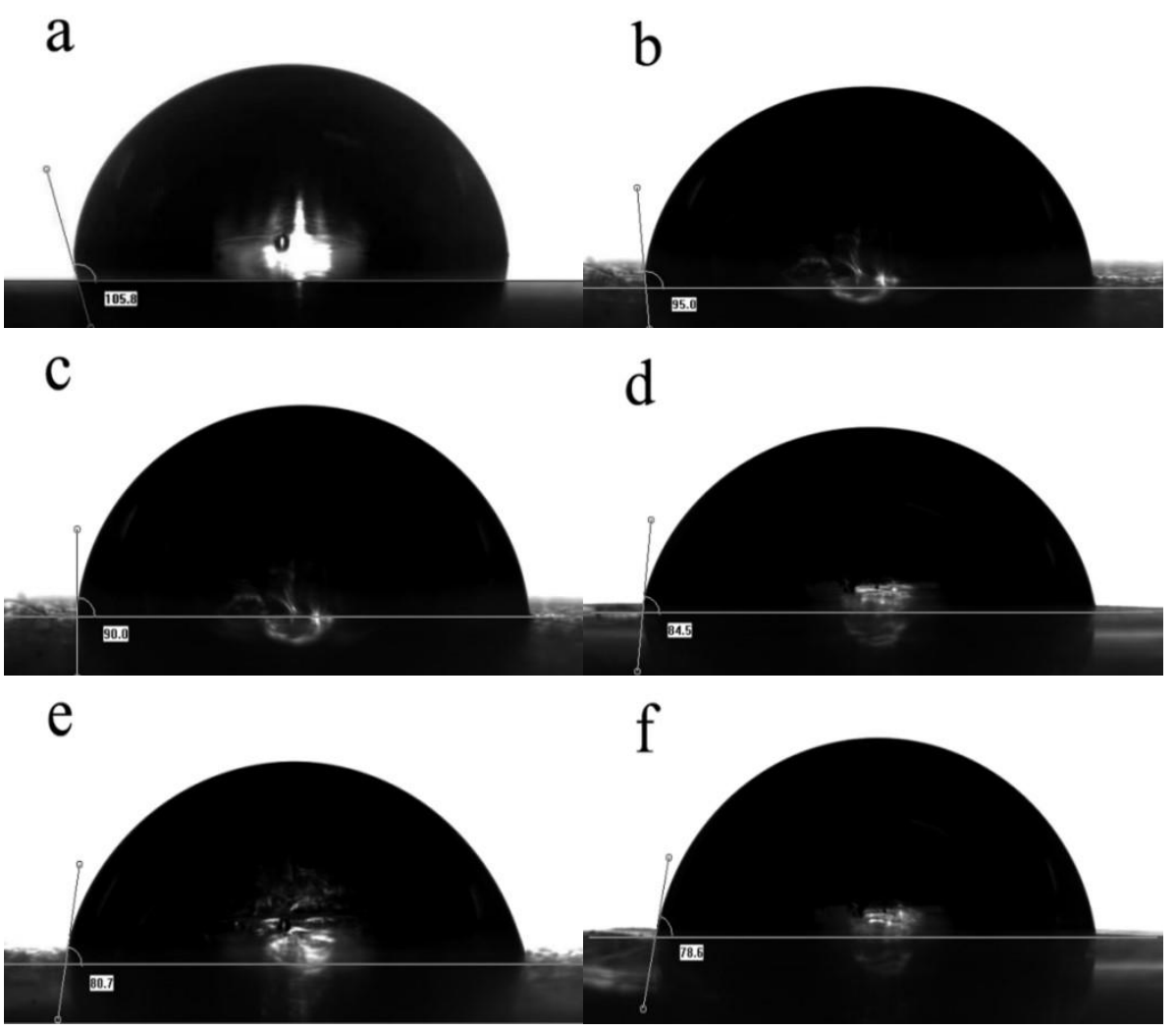

Fig. 9. The contact angle of the pure EP sample and the different NFC content composite waterbased coated film

\section{X-ray Diffraction (XRD) Analysis of the Cellulose Nanofibrils (NFC)} Composite Epoxy Resin (EP) Waterborne Coated Film

Figure 10 shows the XRD images of the pure EP sample and the NFC/EP waterborne coated film.

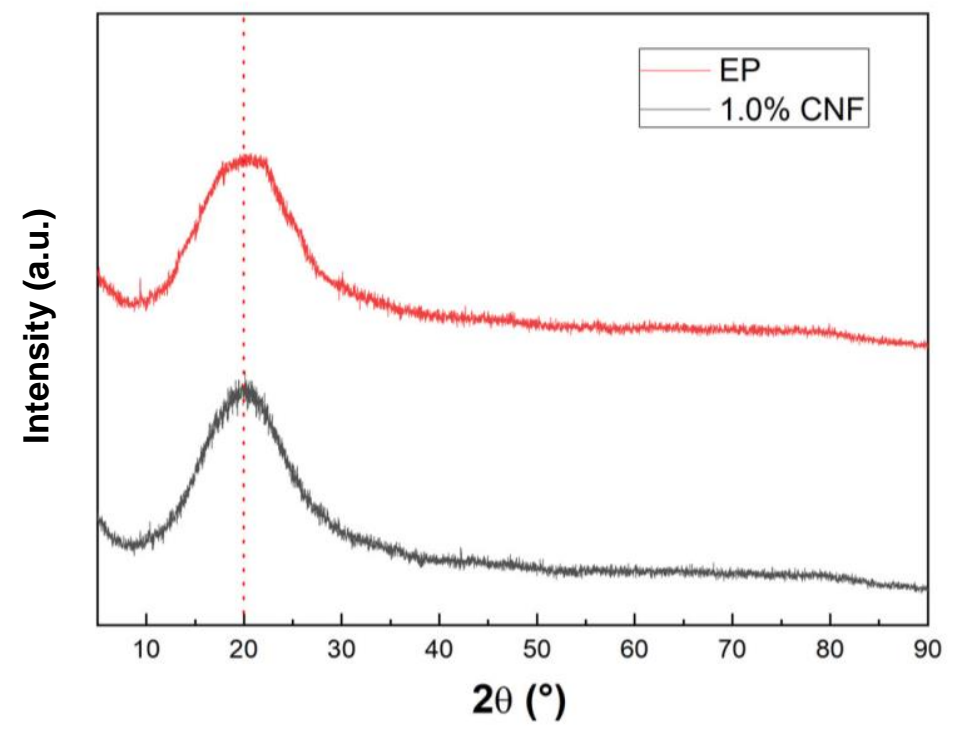

Fig. 10. The X-ray diffraction image of the pure EP sample and the $1.0 \%$ NFC composite waterbased coated film 
According to the above analysis, when the NFC content was $1.0 \%$, the performance of the coating was improved; therefore, the 1.0\% NFC EP water-based coating and pure EP were analyzed via XRD in order to compare the structure change of the coated film after adding NFC. As can be seen in Fig. 10, the pure EP film had only one bump peak in the region of $2 \theta=20^{\circ}$, reflecting the unique structure of an EP amorphous polymer. The diffraction peak from the $1.0 \%$ NFC content sample is similar to the shape and position of the pure EP coated film, and because the NFC content is low, there is no special peak for NFC. The results showed that the mechanical properties and thermal stability of the $1.0 \%$ NFC EP waterborne coated film were improved, and the state and structure of coating were not affected.

\section{Dynamic Mechanical Thermal Analysis (DMA) Analysis of the Cellulose Nanofibrils (NFC) Composite Epoxy Resin (EP) Waterborne Coated Film}

Through the above analysis, the better content of NFC is $1.0 \%$, so the DMA test (López-Suevos et al. 2010) for NFC/EP coated film with this content was carried out. It can be seen from the Fig. 11 that the storage modulus of EP film was $2096 \mathrm{MPa}$ and the storage modulus of $1.0 \%$ NFC sample was $1515 \mathrm{MPa}$. When the addition amount of NFC was $1.0 \%$, the storage modulus of the $\mathrm{EP} / \mathrm{NFC}$ water-based coating system decreased. This is because NFC is effectively integrated into the three-dimensional and highly cross-linked rigid network of EP, which reduces the rigidity of the EP system and makes it flexible. Its storage modulus decreases, and the results show that the addition of NFC to EP increases the toughness of the system, indicating that the composite material has better impact performance. The result was consistent with the characteristics and the characterization results of its mechanical properties.

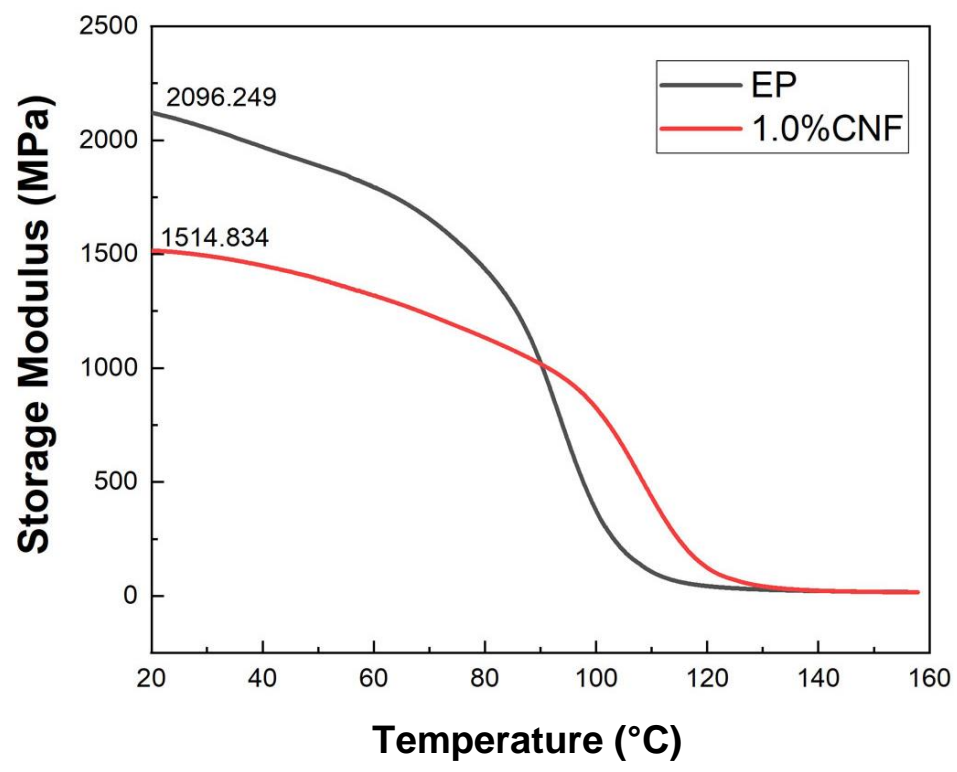

Fig. 11. DMA curve of EP and 1.0\% NFC coated film

\section{Transmission Electron Microscopy (TEM) Analysis of the Cellulose Nanofibrils (NFC) Composite Epoxy Resin (EP) Waterborne Coating}

Figure 12 shows the TEM images of the EP composite waterborne coating with $1.0 \%$ NFC added. Figures 12a and 12b show the enlarged images at $200 \mathrm{~nm}$, and Fig. 12c and 
$12 \mathrm{~d}$ show the enlarged images at $100 \mathrm{~nm}$. NFC has large specific surface area, high aspect ratio, strong surface activity, and interaction between nano-molecules. It can be clearly seen from the figure that the $1.0 \%$ content of NFC was distributed in the water-based paint. The NFC was in the form of filaments, and the molecules were closely intertwined and entangled to form a network structure.

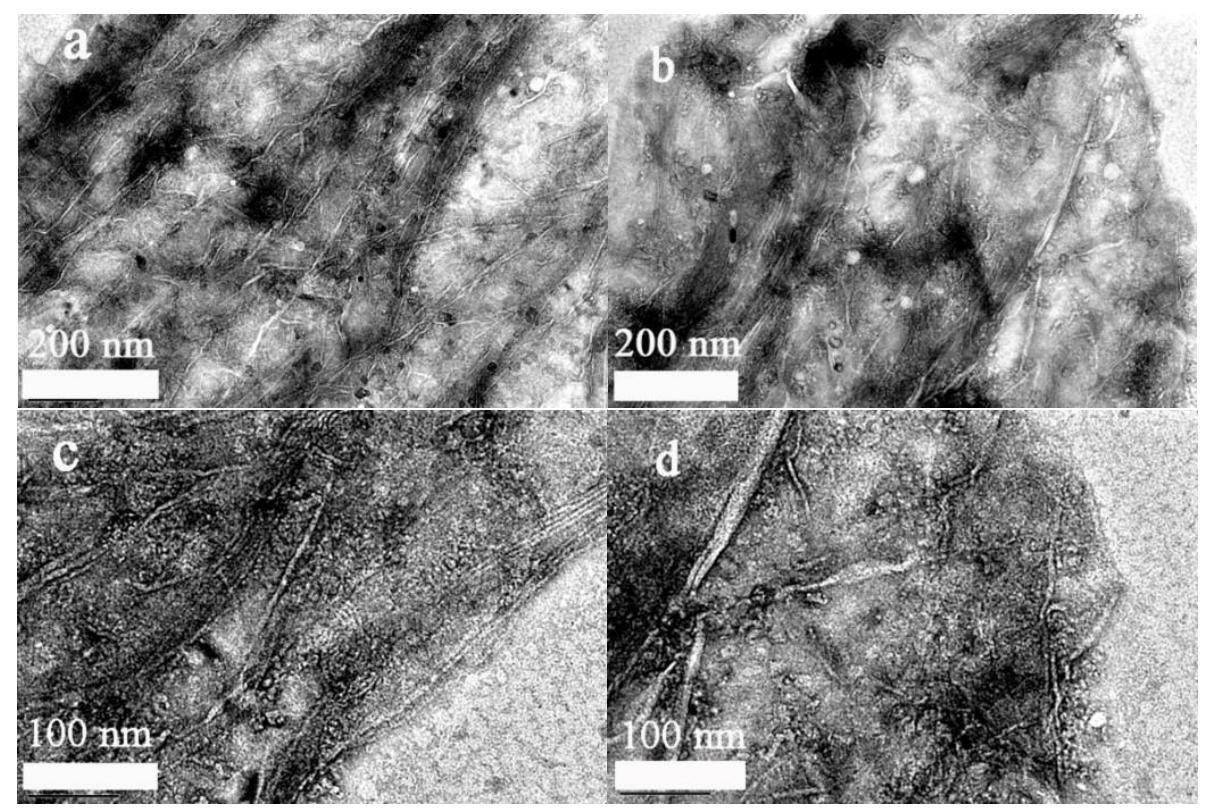

Fig. 12. TEM images of the $1.0 \%$ NFC composite coating ( $a$ and $b$ : The enlarged images at 200 $\mathrm{nm}$. $\mathrm{c}$ and $\mathrm{d}$ : The enlarged images at $100 \mathrm{~nm}$.

\section{Effect of the Addition of Cellulose Nanofibrils (NFC) on the Friction and Wear Properties of Composite Coated Film}

Figure 13 shows that the friction coefficient fluctuated greatly in the initial stage of the test. After about a few minutes, the friction coefficient stabilized. Without the addition of NFC, the friction coefficient increased faster. When the friction time was 30 minutes, the friction coefficient was 0.412 and it continued to rise. When the amount of NFC was $1.0 \%$, the friction coefficient was 0.171 , which is the same as the friction coefficient without NFC. Compared with EP water-based paint, it was reduced by $58.5 \%$. Comparing the two curves at the same time, it can be seen that the friction coefficient of the composite paint after adding NFC decreased. When the friction time gradually increased, the friction coefficient curve gradually became flat and basically remained unchanged.

During the test process, due to the addition of NFC, the surface roughness of the waterborne composite coated film increased, and the combination of the EP waterborne coated film and NFC was better. At the same time, due to the addition of NFC, the thermal stability of the composite system increased, and the composite system was not easily deformed when subjected to the same friction and action temperature. When the steel ball applied friction to the composite coated film, the actual contact area between the steel ball and the composite coated film decreased, since the surface roughness of the composite coated film increased. As such, the friction force acting on the coated film also decreased correspondingly, and the phenomenon of deformation and adhesion of the coating was greatly reduced. This is because NFC has the advantages of a large specific surface area and a high mechanical strength. When friction and wear force are applied to the composite 
coated film, the NFC can bear most of the force, which protects the composite system from damage. At the same time, since the hardness of the EP is lower than the hardness of the NFC, plastic deformation will occur when friction is applied due to the low hardness of the EP, which has a solid lubrication effect on the coated film. According to the above data analysis, the composite coating with NFC was better than the pure EP water-based coated film in terms of friction and wear performance.

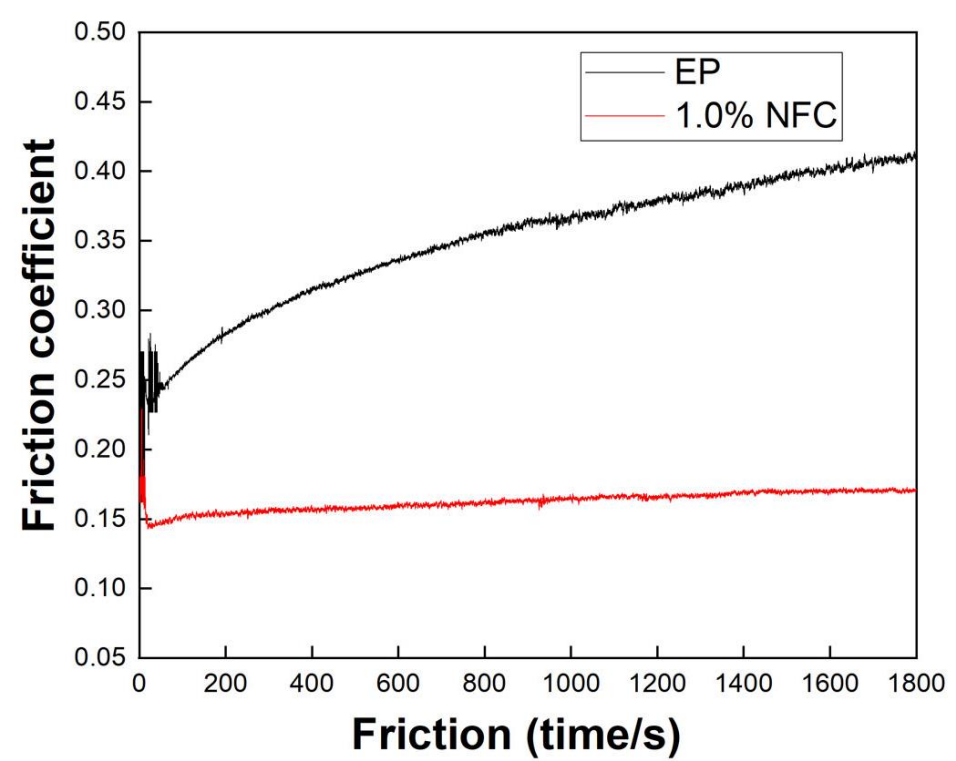

Fig. 13. The friction coefficient curve of the coated film of pure EP and the composite waterbased coated film of $1.0 \%$ NFC

\section{Wear Surface and Mechanism Analysis}

The pure EP SEM images (Figs. 14a and 14b) show the samples after coated film wear. Because EP coated film was brittle and easy to fracture and had poor wear resistance, figures labeled with red circles showed the coated film surface with deep wear marks. Such specimens were rough and uneven after wear. The surface of the groove after wear mainly was in the form of a fracture crack and falling off block, resulting in a furrow effect. What's more, a large number of cracks appeared in the severely worn area, resulting in flake peeling of the EP coated film on the worn surface. The primary wear types were fatigue wear and adhesive wear. This is primarily because the temperature of the pure EP coating will gradually rise when subjected to friction and wear, and its thermal stability is low. Therefore, when the pure EP coated film reaches a certain temperature, plastic deformation will occur, as well as the plastic flow phenomenon. When the friction is greater than the shear strength, it will lead to EP molecular chain fracture, resulting in wear off. Adhesive wear occurs when it is attached to a frictional object.

As shown in Figs. 14c and 14d, after the addition of NFC to the EP coating, the wear surface was relatively smooth, the wear after the crack was greatly reduced, only a small amount of wear loss occurred, and the wear type was primarily abrasive wear. This shows that the pure EP coated film with NFC enhanced the complex flexibility system. Therefore, the friction and wear performance were improved. Combining Fig. 10 and Fig. 15 , one can see the action mechanism of NFC in the composite water-based coated film. 


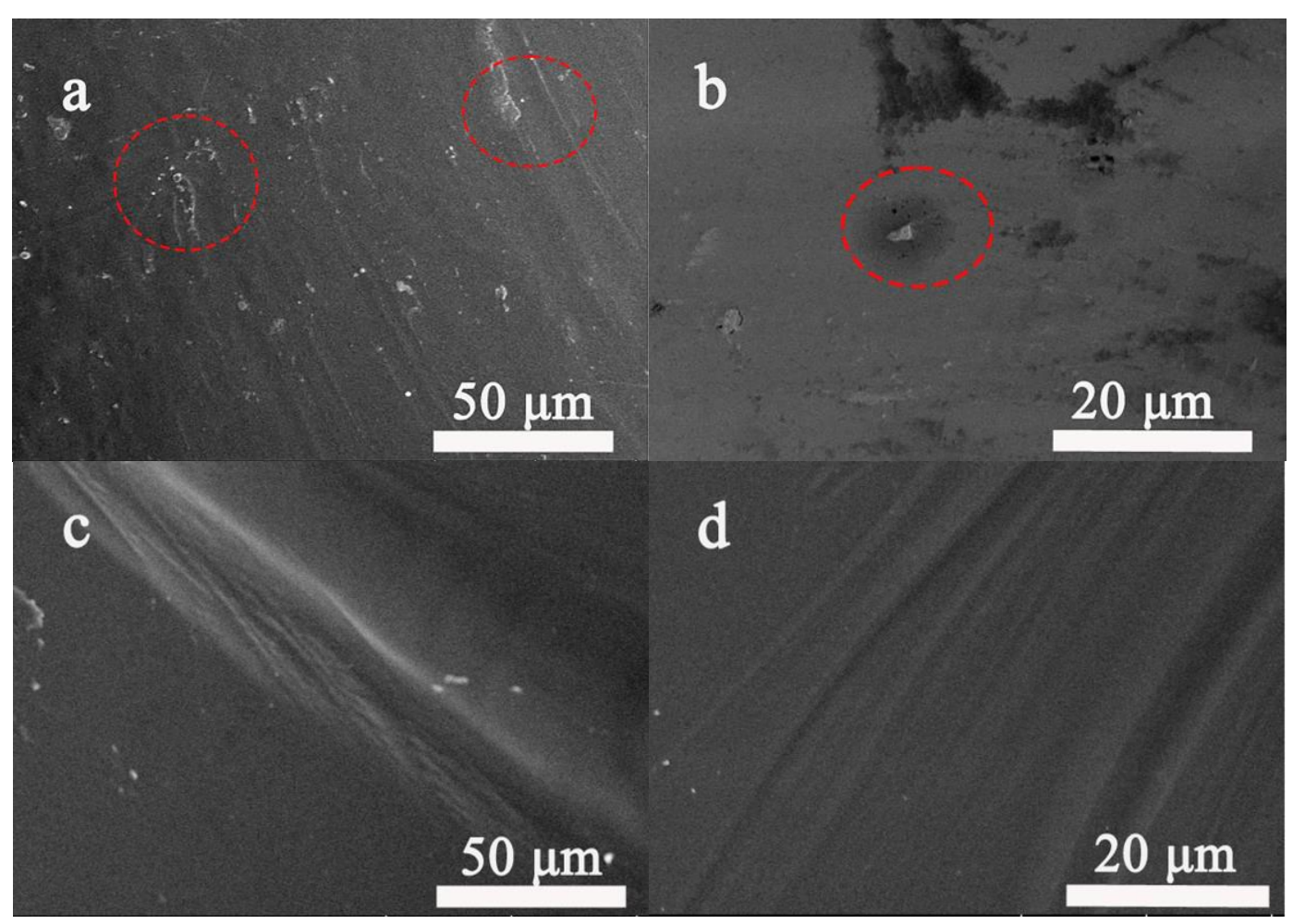

Fig. 14. SEM image of the pure EP sample and the 1.0\% NFC composite water-based coated film after abrasion ( $a$ and $b$ : SEM image of the pure EP coated film. $c$ and $d: 1.0 \%$ NFC composite water-based coated film)

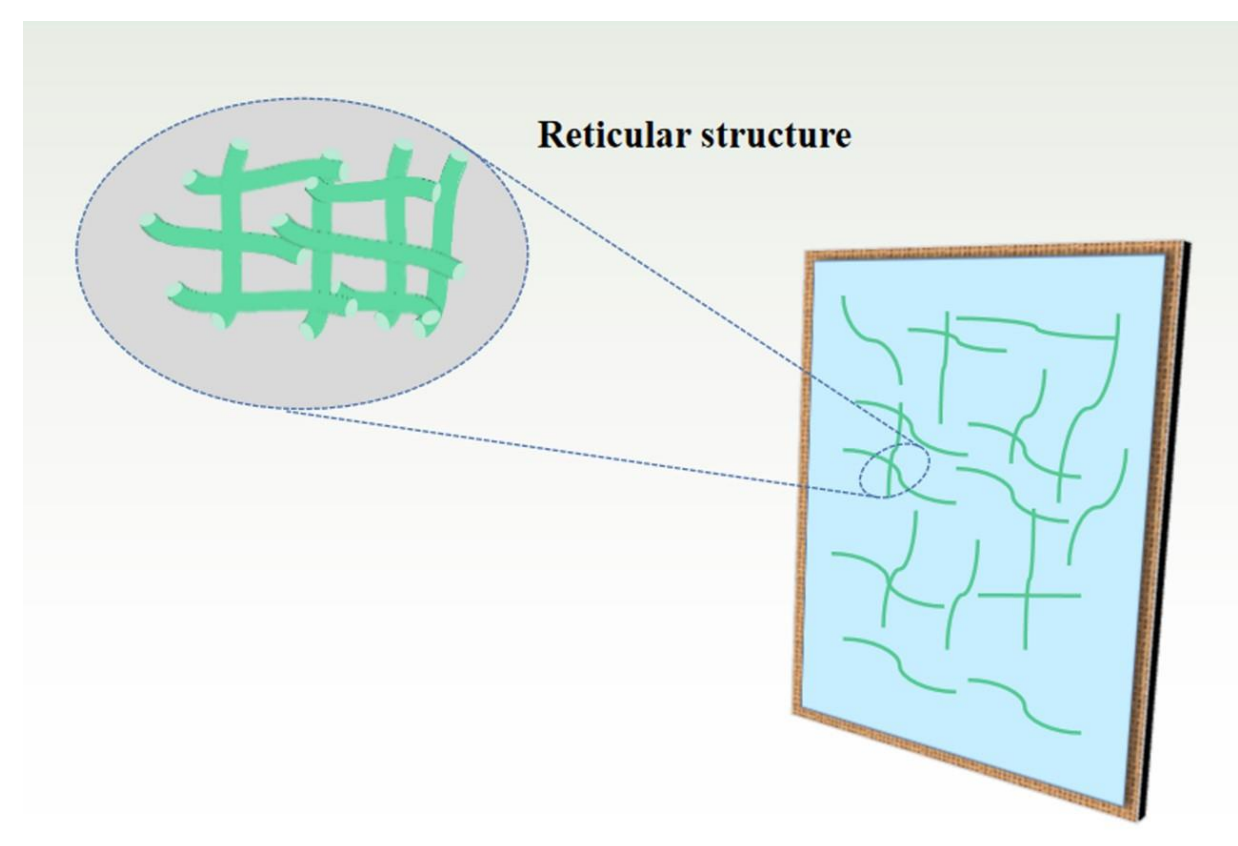

Fig. 15. Schematic diagram of NFC in coated films

NFC is a fine filamentous structure, with a large aspect ratio; when it is added to an EP waterborne coating, it can penetrate the whole system, and the NFC can overlap to form a network structure, improving the cross-linking effect between the EP molecules and the 
curing agent. In addition, NFC has a high mechanical strength and elastic modulus, and large specific surface area characteristics. These attributes, when combined with EP, can increase the hardness of the composite system after mixing. Therefore, when friction and wear effects occur, the addition of NFC can enhance the bearing capacity of the EP, shouldering the bulk of the force. At the same time, when friction and wear are applied, debris stripping becomes difficulty, and crack extension does not occur as easily. The addition of NFC can improve the brittleness, fracture, and plastic deformation properties of the coated film, and reduce the generation of wear debris.

\section{CONCLUSIONS}

1. The addition of nanofibrillated cellulose (NFC) can improve the comprehensive properties of epoxy resin (EP) waterborne coated film. When the NFC content was controlled at $1.0 \%$, the flexibility was $1 \mathrm{~mm}$, the adhesion was 0 , the hardness was 4 $\mathrm{H}$, the wear value was $15 \mathrm{mg} / 100 \mathrm{r}$, the impact resistance was $49 \mathrm{~cm}$, and the gloss was 85 Gs. The NFC molecules were closely intertwined, forming a network structure in EP matrix, not affecting the structure and state of the coated film. SEM micrographs revealed rough scaly cracks, which showed obvious ductile fracture. The thermal stability of the EP waterborne coated film was improved by the addition of NFC.

2. According to the friction and wear test, the friction coefficient of pure EP was 0.412, and the friction curve kept increasing. The friction coefficient of EP was 0.171 when the amount of NFC was $1.0 \%$, which was $58.50 \%$ lower than the friction coefficient of the EP waterborne coated film without NFC, and the friction curve was gentle. The surface after undergoing wear showed that the surface of the pure EP coated film was rough and had a large number of cracks, with the primary wear types being fatigue wear and adhesive wear. After the addition of NFC, the wear surface of the composite coated film was relatively smooth, with only a small amount of wear off, and the primary wear type was abrasive wear.

\section{ACKNOWLEDGMENTS}

This work was supported by the National Natural Science Foundation of China (Grant No. 21767022), the Autonomous Region Undergraduate Innovation and Entrepreneurship Training Program (202110129007), and the Natural Science Foundation of Inner Mongolia Autonomous Region (Grant No. 2019BS03014).

\section{REFERENCES CITED}

Arjmand, M., and Shojaei, A. (2011). "Tribological characteristics of rubber-based friction materials," Tribology Letters 41(2), 325-336. DOI: 10.1007/s11249-0109715-0

Azeez, A. A., Rhee, K. Y., Park, S. J., and Hui, D. (2013). "Epoxy clay nanocomposites Processing, properties and applications: A review," Composites Part B:

Engineering 45(1), 308-320. DOI: 10.1016/j.compositesb.2012.04.012 
Bondeson, D., Mathew, A., and Oksman, K. (2006). "Optimization of the isolation of nanocrystals from microcrystalline cellulose by acid hydrolysis," Cellulose 13(2), 171-180. DOI: 10.1007/s10570-006-9061-4

Burris, D. L., Boesl, B., Bourne, G. R., and Sawyer, W. G. (2010). “Polymeric nanocomposites for tribological applications," Macromolecular Materials and Engineering 292(4), 387-402. DOI: 10.1002/mame.200600416

Cao, X., Dong, H., and Li, C. M. (2007). "New nanocomposite materials reinforced with flax cellulose nanocrystals in waterborne polyurethane," Biomacromolecules 8(3), 899-904. DOI: $10.1021 / \mathrm{bm} 0610368$

Carvalho Benini, K. C. C., Voorwald, H. J. C., Hilário Cioffi, M. O., Rezende, M. C., and Arantes, V. (2018). "Preparation of nanocellulose from Imperata brasiliensis grass using taguchi method," Carbohydrate Polymers 192, 337-346. DOI: 10.1016/j.carbpol.2018.03.055

Chandran, A. R., and Radhika, N. (2019). "Investigation on mechanical properties and wear behaviour of chopped carbon-basalt epoxy hybrid composite," Materials Research Express 6(10), 1-10. DOI: 10.1088/2053-1591/ab3587

Chang, L., and Zhang, Z. (2006). "Tribological properties of epoxy nanocomposites: Part II. A combinative effect of short carbon fibre with nano-TiO, ${ }_{2}$, Wear 260(7-8), 869878. DOI: $10.1016 /$ j.wear.2005.04.002

Chengyin, M., Deng, C., and Wenji, Z. (2007). "Waterborne epoxy resin modified by AMPS," Journal of Wuhan University of Technology-Mater. Sci. Ed. 22(4), 649-652. DOI: $10.1007 / \mathrm{s} 11595-006-4649-\mathrm{y}$

Dieter, K., Friederike, K., Moritz, S., Lindström, T., Ankerfors, M., Gray, D., and Dorris, A. (2011). "Nanocelluloses: A new family of nature-based materials," Angewandte Chemie International Edition 50(24), 5438-5466. DOI: 10.1002/anie.201001273

Doyle, C. D. (1961). "Estimating thermal stability of experimental polymers by empirical thermogravimetric analysis," Analytical Chemistry 33(1), 77-79. DOI: 10.1021/ac60169a022

Düzcükoğlu, H., Ekinci, Ş., Şahin, Ö. S., Avci, A., Ekrem, M., and Ünaldi, M. (2015). "Enhancement of wear and friction characteristics of epoxy resin by multiwalled carbon nanotube and boron nitride nanoparticles," Tribology Transactions 58(4), 635642. DOI: 10.1080/10402004.2014.998358

Domun, N., Hadavinia, H., Zhang, T., Sainsbury, T., Liaghat, G.H., and Vahid, S. (2015). "Improving the fracture toughness and the strength of epoxy using nanomaterials - A review of the current status," Nanoscale 7(23), 10294-10329. DOI:10.1039/c5nr01354b

Espinosa, S. C., Kuhnt, T., Foster, E. J., and Weder, C. (2013). "Isolation of thermally stable cellulose nanocrystals by phosphoric acid hydrolysis," Biomacromolecules 14(4), 1223-1230. DOI: 10.1021/bm400219u

Fahma, F., Takemura, A., and Saito, Y. (2014). "Acetylation and stepwise solventexchange to modify hydrophilic cellulose whiskers to polychloroprene-compatible nanofiller," Cellulose 21(4), 2519-2527. DOI: 10.1007/s10570-014-0294-3

Fei, Y., Wu, Q., Yong, L., Guo, W., and Xu, Y. (2008). “Thermal decomposition kinetics of natural fibers: activation energy with dynamic thermogravimetric analysis," Polymer Degradation \& Stability 93(1), 90-98. DOI: 10.1016/j.polymdegradstab.2007.10.012

Findik, F. (2014). "Latest progress on tribological properties of industrial materials," Materials \& Design 57, 218-244. DOI: 10.1016/j.matdes.2013.12.028 
Giorcelli, M., Savi, P., Khan, A., and Tagliaferro, A. (2019). "Analysis of biochar with different pyrolysis temperatures used as filler in epoxy resin composites," Biomass and Bioenergy 122(3), 466-471. DOI: 10.1016/j.biombioe.2019.01.007

GB/T 1728 (1989). "Methods of test for drying time of coatings of paints and putties," Standardization Administration of China, Beijing, China.

GB/T 1731 (1993). "Determination of flexibility of films," Standardization Administration of China, Beijing, China.

GB/T 4893.8 (2013). "Test of surface coatings of furniture - Part 8: Determination of wearability," Standardization Administration of China, Beijing, China.

GB/T 5210 (2006). "Paints and varnishes - Pull-off test for adhesion," Standardization Administration of China, Beijing, China.

GB/T 6773 (1996). "Pencil determination method of paint film hardness," Standardization Administration of China, Beijing, China.

GB/T 9754 (2007). "Paints and varnishes - Determination of specular gloss of nonmetallic paint films at $20^{\circ}, 60^{\circ}$ and $85^{\circ}$," Standardization Administration of China, Beijing, China.

Isogai, A., Saito, T., and Fukuzumi, H. (2011). "Tempo-oxidized cellulose nanofibers," Nanoscale 3(1), 71-85. DOI: 10.1039/C0NR00583E

Jin, F.-L., Li, X., and Park, S.-J. (2015). "Synthesis and application of epoxy resins: A review," Journal of Industrial and Engineering Chemistry 29, 1-11. DOI: 10.1016/j.jiec.2015.03.026

Kang, Y., Chen, X., Song, S., Yu, L., and Zhang, P. (2012). "Friction and wear behavior of nanosilica-filled epoxy resin composite coatings," Applied Surface Science 258(17), 6384-6390. DOI: 10.1016/j.apsusc.2012.03.046

Koshevar, V. D., Shinkareva, E. V., Fadeev, N. M., and Budeiko, N. L. (2009). "Curing of aqueous epoxy dispersions in the presence of a cycloaliphatic amine," Russian Journal of Applied Chemistry 82(2), 301-306. DOI: 10.1134/s1070427209020256

Kostrzewa, M., Hausnerova, B., Bakar, M., and Dalka, M. (2011). "Property evaluation and structure analysis of polyurethane/epoxy graft interpenetrating polymer networks," Journal of Applied Polymer Science 122(3), 1722-1730. DOI: 10.1002/app.34070

Li, F., Hu, K., Li, J., and Zhao, B. (2001). "The friction and wear characteristics of nanometer $\mathrm{ZnO}$ filled polytetrafluoroethylene," Wear 249(10-11), 877-882. DOI: 10.1016/S0043-1648(01)00816-X

Liu, M., Mao, X., Zhu, H., Lin, A., and Wang, D. (2013). "Water and corrosion resistance of epoxy-acrylic-amine waterborne coatings: Effects of resin molecular weight, polar group and hydrophobic segment," Corrosion Science 75, 106-113. DOI: 10.1016/j.corsci.2013.05.020

Lu, G., Sun, J., and Zhou, Q. (2007). "Synthesis and characterization of waterborne epoxy curing agent modified by silane," Chinese Journal of Chemical Engineering 15(6), 899-905. DOI: 10.1016/S1004-9541(08)60022-1

López-Suevos, F., Eyholzer, C., Bordeanu, N., and Richter, K. (2010). "DMA analysis and wood bonding of PVAc latex reinforced with cellulose nanofibrils," Cellulose 17(2), 387-398. DOI: 10.1007/s 10570-010-9396-8

Mohan, T. P., and Kanny, K. (2011). "Water barrier properties of nanoclay filled sisal fibre reinforced EPoxy composites," Composites Part A: Applied Science and Manufacturing 42(4), 385-393. DOI: 10.1016/j.compositesa.2010.12.010

Negi, A. S., Katiyar, J. K., Kumar, S., Kumar, N., and Patel, V. K. (2019). 
"Physicomechanical and abrasive wear properties of hemp/Kevlar/carbon reinforced hybrid epoxy composites," Materials Research Express 6(11), 1-14. DOI: 10.1088/2053-1591/ab438d

Raghavendra, G., Ojha, S., Acharya, S. K., and Pal, S. K. (2013). "Jute fiber reinforced epoxy composites and comparison with the glass and neat epoxy composites,"

Journal of Composite Materials 48(20), 2537-2547. DOI: 10.1177/0021998313499955

Rahimi, M., and Behrooz, R. (2011). "Effect of cellulose characteristic and hydrolyze conditions on morphology and size of nanocrystal cellulose extracted from wheat straw" International Journal of Polymeric Materials and Polymeric Biomaterials 60(8), 529-541. DOI: 10.1080/00914037.2010.531820

Ribeiro, R. S. A., Pohlmann, B. C., Calado, V., Bojorge, N., and Pereira Jr., N. (2019). "Production of nanocellulose by enzymatic hydrolysis: Trends and challenges," Engineering in Life Sciences 19(4), 279-291. DOI: 10.1002/elsc.201800158

Roy, D., Semsarilar, M., Guthrie, J., and Perrier, S. (2009). "Cellulose modification by polymer grafting: A review," Chemical Society Reviews 38(7), 2046-2064. DOI: $10.1039 / \mathrm{b} 808639 \mathrm{~g}$

Saba, N., Mohammad, F., Pervaiz, M., Jawaid, M., Alothman, O. Y., and Sain, M. (2017). "Mechanical, morphological and structural properties of cellulose nanofibers reinforced epoxy composites," International Journal of Biological Macromolecules 97, 190-200. DOI: 10.1016/j.ijbiomac.2017.01.029

Salas, C., Nypelö, T., Rodriguez-Abreu, C., Carillo, C., and Rojas, O. J. (2014). "Nanocellulose properties and applications in colloids and interfaces," Current Opinion in Colloid \& Interface Science. 19(5), 383-396. DOI:

10.1016/j.cocis.2014.10.003

Sanes, J., Carrión, F. J., and Bermúdez, M. D. (2010). "Effect of the addition of room temperature ionic liquid and $\mathrm{ZnO}$ nanoparticles on the wear and scratch resistance of epoxy resin," Wear 268(11-12), 1295-1302. DOI: 10.1016/j.wear.2010.01.024

Shi, G., Zhang, M. Q., Rong, M. Z., Wetzel, B., and Friedrich, K. (2003). "Friction and wear of low nanometer $\mathrm{Si}_{3} \mathrm{~N}_{4}$ filled epoxy composites," Wear 254(7-8), 784-796. DOI: 10.1016/S0043-1648(03)00190-X

Shikha, D., Kamani, P. K., and Shukla, M. C. (2003). " Studies on synthesis of waterborne epoxy ester based on RBO fatty acids," Progress in Organic Coatings 47(2), 87-94. DOI: 10.1016/S0300-9440(02)00159-5

Sujan, D., Nguong, C. W., Lee, S. N. B., and Zewge, M. G. (2014). "Wear properties of oil palm cellulose fibre reinforced polymer composites," Advanced Materials Research 845, 81-85. DOI: 10.4028/www.scientific.net/AMR.845.81

Sun, H., Ni, W., Yuan, B., Wang, T., Li, P., and Liu, Y. (2013). "Synthesis and characterization of emulsion-type curing agent of water-borne epoxy resin," Journal of Applied Polymer Science 130(4), 2652-2659. DOI: 10.1002/app.39485

Tan, Y., Liu, Y., Chen, W., Liu, Y., Wang, Q., Li, J., and Yu, H. (2016). “Homogeneous dispersion of cellulose nanofibers in waterborne acrylic coatings with improved properties and unreduced transparency," ACS Sustainable Chemistry \& Engineering 4(7), 3766-3772. DOI: 10.1021/acssuschemeng.6b00415

Tian, J., Tan, Y., Zhang, Z., Wang, X., Xu, T., and Tang, B. (2020). “Effects of hyperbranched polyesters covalent functionalized multi-walled carbon nanotubes on the mechanical and tribological properties of epoxy composites," Materials Research Express 7(1), 1-15. DOI: 10.1088/2053-1591/ab54dc 
Thomas, R., Ding, Y., He, Y., Le, Y., Moldenaers, P., Yang, W., Tibor, C., and Thomas, S. (2008). "Miscibility, morphology, thermal, and mechanical properties of a dgeba based epoxy resin toughened with a liquid rubber," Polymer 49(1), 278-294. DOI: 10.1016/j.polymer.2007.11.030

Wu, S., Guo, Q., Peng, S., Hameed, N., and Mai, Y. W. (2012). "Toughening epoxy thermosets with block ionomer complexes: A nanostructure-mechanical property correlation," Macromolecules 45(9), 3829-3840. DOI: 10.1021/ma300458y

Yu, W., Fu, J., Dong, X., Chen, L., Jia, H., and Shi, L. (2013). "Highly populated and nearly monodispersed nanosilica particles in an organic medium and their epoxy nanocomposites," ACS Applied Materials \& Interfaces 5(18), 8897-8906. DOI: 10.1021/am402845d

Zhang, Y., Song, P., Liu, H., Li, Q., and Fu, S. (2016). "Morphology, healing and mechanical performance of nanofibrillated cellulose reinforced poly( $\varepsilon$-caprolactone)/epoxy composites," Composites Science \& Technology 125, 62-70. DOI: 10.1016/j.compscitech.2016.01.008

Zhang, K., Huang, C., Fang, Q., and Lu, Q. (2017). "Synthesis of a self-emulsifiable waterborne epoxy curing agent based on glycidyl tertiary carboxylic ester and its cure characteristics," Journal of Applied Polymer Science 134(6), 442-454. DOI: 10.1002/app.44246

Zhao, B., and Tao, B. (2019). "Improving the tribological performance of epoxy coatings by the synergistic effect between dehydrated ethylenediamine modified graphene and polytetrafluoroethylene," Carbon 144, 481-491. DOI: 10.1016/j.carbon.2018.12.092

Zhong, Y., Wang, K., Liu, Y., and Wang, X. (2021). "Extraction and characterization of Salix cellulose," Guangzhou Chemical Industry 49(09), 69-72, 133, China.

Article submitted: August 7, 2021; Peer review completed: October 17, 2021; Revised version received and accepted: December 4, 2021; Published: December 8, 2021.

DOI: 10.15376/biores.17.1.802-825 